\title{
The relationship between Modic changes and intervertebral disc degeneration
}

\author{
Juhani H. Määttä ${ }^{1}$, Alex MacGregor ${ }^{2}$, Jaro Karppinen ${ }^{1,3,4}$ and Frances M. K. Williams ${ }^{2 *}$
}

\begin{abstract}
Background: Recent reported results have added to the weight of evidence supporting association between disc degeneration and Modic changes. Endplate or Modic changes are also associated with increased body mass index. The most recent study from Teichtahl et al. titled 'Modic changes in the lumbar spine and their association with body composition, fat distribution and intervertebral disc height - a 3.0 T-MRI study' showed associations of Modic changes with quantitatively measured reduced disc height and fat mass index. However, there were some facts, which we would like to address in this Correspondence to their article.

Discussion: The different components of intervertebral disc degeneration such as loss of disc height and disc signal intensity have already been shown associated with endplate changes - but not disc height if it is assessed using newer more precise methods of quantitation of disc height. A possible protective effect of different adiposity distribution in the body to Modic change development would be of interest if observed in a longitudinal study in the future.
\end{abstract}

Summary: Modic changes have been associated with different components of intervertebral disc degeneration such as loss of disc height and disc signal intensity previously. The influence of body fat distribution on endplate changes would be interesting to study longitudinally.

Keywords: Body mass index, Disc degeneration, Modic change

\section{Background}

We were interested to read the recently published study on Modic changes by Teichtahl and Urquhart et al. [1] which used $3 \mathrm{~T}$ magnetic resonance imaging of the spine in a small population sample. There is a pressing need to understand better the mechanisms behind the common and costly social problem of low back pain.

We wonder what the rationale for studying fat distribution was when the authors reference a paper showing no evidence of an effect of body mass index (BMI) [2]. In fact, there are several studies published already which have examined endplate changes (i.e. Modic changes). They provide evidence for increasing BMI being associated with endplate changes. Body mass index and waist circumference were both associated with Modic type 2 change among middle-aged male workers in Finland [3]; and among Spanish chronic low back pain patients any

\footnotetext{
* Correspondence: Frances.williams@kcl.ac.uk;

${ }^{2}$ Department of Twin Research and Genetic Epidemiology, King's College

London, St Thomas' Hospital, London SE1 7EH, UK

Full list of author information is available at the end of the article
}

Modic change was associated with increasing BMI [4]. Finally, our recent study of a predominantly female twin sample (TwinsUK) found association with increasing BMI and endplate changes [5]. More recently, obesity was proposed to affect to Modic change development through increased spinal forces, i.e. hyperloading, but also may exert influence on adipogenesis, hematopoiesis and osteogenesis [6].

Our work using the TwinsUK registry [5], as well as that of Kerttula et al. [7], examined endplate changes and features of intervertebral disc and found an association with both disc height loss and change in disc signal intensity. While our work lacks T1-weighted images and therefore isn't strictly as Modic described, the sample is more than ten fold larger than the reported Australian study and likely presents robust findings. Even though disc height loss has been associated with Modic changes, it is true that previous studies have evaluated disc height by semi-quantitative scale as applied by trained personnel using a reference atlas, and not quantitatively. 
Quantitative measurement is an advantage in the study of Teichtahl et al. [1], but it should be noted that the association of disc height loss and Modic changes have been reported previously.

It would be of interest to determine whether different distributions of adiposity really have opposite effects or whether this reflects chance findings in a cross-sectional snapshot in endplate progression. In TwinsUK data we observed an association between disc height and disc bulge at baseline and an incident endplate change during follow-up of over a decade. Finally, most importantly of all, we showed both intervertebral disc degeneration and endplate changes to be independent predictors of episodes of severe and disabling low back pain.

\title{
Response to "The relationship between Modic changes and intervertebral disc degeneration"
}

\author{
Andrew J. Teichtahl ${ }^{1,2}$, Donna M. Urquhart', Yuanyuan Wang ${ }^{1}$, Anita E. Wluka', Richard O'Sullivan ${ }^{3,4}$, \\ Graeme Jones $^{5}$ and Flavia M. Cicuttini ${ }^{i^{*}}$ \\ 'Department of Epidemiology and Preventive Medicine, School of Public Health and Preventive Medicine, Monash \\ University, Alfred Hospital, Melbourne, VIC 3004, Australia \\ ${ }^{2}$ Baker IDI Heart and Diabetes Institute, Commercial Road, Melbourne, VIC 3004, Australia \\ ${ }^{3}$ Healthcare Imaging Services, Epworth Hospital, Richmond, Melbourne, VIC 3121, Australia \\ ${ }^{4}$ Department of Medicine, Central Clinical School, Monash University, Melbourne, VIC 3004, Australia \\ ${ }^{5}$ Menzies Research Institute, Private bag 23, Hobart, TAS 7000, Australia
}

We thank Määttä et al. for their interest in our work [1]. We agree that a strength of our study is the quantitative measure of intervertebral disc height. This complements the findings from the TwinsUK registry whereby endplate changes (i.e. Modic changes) were associated with semi-quantitative features of intervertebral disc degeneration [5]. We offer intervertebral disc height as a validated, quantitative, easily measured and sensitive alternative to qualitative or semi-quantitative measures of disc degeneration [8].

A major aim of our study was to determine whether body composition was a risk factor for Modic change, with the hypothesis being that adiposity would be a risk factor for such lesions. Previous attempts to examine the association between body mass index (BMI) and Modic change, whether demonstrating significant $[3,4]$ or nonsignificant [2] findings, cannot specifically comment on the contribution of adiposity: BMI cannot discriminate adipose or non-adipose mass, nor can it measure the distribution of fat. This is of particular interest since Modic type 2 change histologically represents fat replacement of the vertebral endplate [9].

Additionally, we agree that it would be of interest to further corroborate the differential effect of android and gynoid fat distribution. Nevertheless, our data is compelling: we have shown statistically significant associations $(p=0.01)$ in different biological directions for the exposure of android and gynoid fat. It would seem unlikely that these disparate associations occurred by chance alone, particularly given our modest sample size which would only serve to reduce our chance of showing significant results.
We welcome further research efforts examining these associations, and agree that longitudinal studies would be particularly helpful in determining the predictive nature of not only structural abnormalities, but also symptoms.

\section{Abbreviation \\ $\mathrm{BMI}$, body mass index}

Acknowledgements

Not applicable.

Funding

Not applicable.

Availability of data and materials

Not applicable.

Authors' contributions

JHM, AM, JK and FMKW contributed in drafting the manuscript and revised it critically for important intellectual content and gave final approval of the version to be published.

Authors' information

Not applicable.

Competing interests

The authors declare that they have no competing interests.

Consent for publication

Not applicable.

Ethics approval and consent to participate

Not applicable.

Author details

${ }^{1}$ Medical Research Center Oulu, Oulu University Hospital and University of Oulu, Oulu, Finland. ${ }^{2}$ Department of Twin Research and Genetic Epidemiology, King's College London, St Thomas' Hospital, London SE1 7EH, UK. ${ }^{3}$ Finnish Institute of Occupational Health, Oulu, Finland. ${ }^{4}$ Faculty of Medicine, Center for Life Course Health Research, University of Oulu, Oulu, Finland. 
Received: 22 April 2016 Accepted: 2 August 2016

\section{Published online: 26 August 2016}

\section{References}

1. Teichtahl AJ, Urquhart DM, Wang Y, Wluka AE, O'Sullivan R, Jones $G$, et al. Modic changes in the lumbar spine and their association with body composition, fat distribution and intervertebral disc height - a 3.0 T-MRI study. BMC Musculoskelet Disord. 2016;17(1):92.

2. Karchevsky M, Schweitzer ME, Carrino JA, Zoga A, Montgomery D, Parker L. Reactive endplate marrow changes: a systematic morphologic and epidemiologic evaluation. Skeletal Radiol. 2005;34(3):125-9.

3. Kuisma M, Karppinen J, Haapea M, Niinimäki J, Ojala R, Heliövaara M, et al. Are the determinants of vertebral endplate changes and severe disc degeneration in the lumbar spine the same? A magnetic resonance imaging study in middle-aged male workers. BMC Musculoskelet Disord. 2008;9:51

4. Arana E, Kovacs FM, Royuela A, Estremera A, Asenjo B, Sarasibar H, et al. Modic changes and associated features in Southern European chronic low back pain patients. Spine J. 2011;11(5):402-11.

5. Määttä JH, Wadge S, MacGregor A, Karppinen J, Williams FM. ISSLS Prize Winner: Vertebral Endplate (Modic) Change is an Independent Risk Factor for Episodes of Severe and Disabling Low Back Pain. Spine (Phila Pa 1976). 2015;40(15):1187-93

6. Dudli S, Fields AJ, Samartzis D, Karppinen J, Lotz JC. Pathobiology of Modic changes. Eur Spine J. 2016 [Epub ahead of print].

7. Kerttula L, Luoma K, Vehmas T, Grönblad M, Kääpä E. Modic type I change may predict rapid progressive, deforming disc degeneration: a prospective 1-year follow-up study. Eur Spine J. 2012;21(6):1135-42.

8. Teichtahl AJ, Urquhart DM, Wang Y, Wluka AE, Heritier S, Cicuttini FM. A Dose-response relationship between severity of disc degeneration and intervertebral disc height in the lumbosacral spine. Arthritis Res Ther. 2015;17:297. doi:10.1186/s13075-015-0820-1.

9. Modic MT, Steinberg PM, Ross JS, Masaryk TJ, Carter JR. Degenerative disk disease: assessment of changes in vertebral body marrow with MR imaging. Radiology. 1988;166(1 Pt 1):193-9.

\section{Submit your next manuscript to BioMed Central and we will help you at every step:}

- We accept pre-submission inquiries

- Our selector tool helps you to find the most relevant journal

- We provide round the clock customer support

- Convenient online submission

- Thorough peer review

- Inclusion in PubMed and all major indexing services

- Maximum visibility for your research

Submit your manuscript at www.biomedcentral.com/submit
Biomed Central 